\title{
In Vitro and In Vivo Study of Poly(ethylene glycol) Conjugated Ibuprofen to Extend the Duration of Action
}

\author{
Anjali NAYAK, Anurekha JaIN *
}

B. R. Nahata College of Pharmacy, Mandsaur 458001, India.

* Corresponding author. E-mail: Anurekha_jain@yahoo.com (A. Jain)

Sci Pharm. 2011; 79: 359-373

doi:10.3797/scipharm.0911-07

Published: $\quad$ March $20^{\text {th }} 2011$

Accepted: $\quad$ March $4^{\text {th }} 2011$

Received: $\quad$ November $14^{\text {th }} 2009$

This article is available from: http://dx.doi.org/10.3797/scipharm.0911-07

(c) Nayak and Jain; licensee Österreichische Apotheker-Verlagsgesellschaft m. b. H., Vienna, Austria.

This is an Open Access article distributed under the terms of the Creative Commons Attribution License (http://creativecommons.org/licenses/by/3.0/), which permits unrestricted use, distribution, and reproduction in any medium, provided the original work is properly cited.

\begin{abstract}
Ibuprofen-polyethylene glycol (PEG) conjugates (PEG-Ibu) were prepared and their potential as a prolonged release system was investigated. Two PEG-Ibu conjugates were synthesized from Ibuprofen and PEG with two different molecular weights by esterification in the presence of DCC and DMAP. The PEG-Ibu conjugates were characterized by FT-IR, ${ }^{1} \mathrm{H}$ NMR, Mass spectroscopy and DSC analysis. The solubility study in aqueous system showed an increase in solubility of conjugates. The dissolution / hydrolysis studies showed a specific acid-base catalysis pattern dependent on the $\mathrm{pH}$ of the medium. This indicated a good chemical stability in aqueous buffer solution of acidic medium and the extended release behavior was found in both prodrugs after 9 hour. The results demonstrate that, in the same condition, the rate of hydrolysis for $P E G_{4000}-I_{b u}$ is slower than other. The Writhing induced by acetic acid experiment and paw edema test after oral administration showed that both conjugates had extended analgesic and anti-inflammatory effects compared with lbuprofen. These results suggest that PEG-Ibu could be a promising NSAID prodrug with an extended pharmacological effect owing to delayed-release of parent drug.
\end{abstract}

\section{Keywords}

Ibuprofen • Poly(ethylene glycol) • Conjugation • Analgesic • Anti-inflammatory 


\section{Introduction}

Non-steroidal anti-inflammatory drugs (NSAIDs) are usually poorly soluble in water [1] and they frequently cause gastrointestinal side effects such as gastric ulceration, bleeding and perforation [2, 3]. Ibuprofen is a non-steroidal anti-inflammatory drug with well known antiinflammatory, antipyretic and analgesic properties. Chemically it is 2-(4-iso-butylphenyl)propanoic acid and is poorly soluble in water $[4,5]$. It is most commonly administered orally and is rapidly absorbed to reach its maximal plasma concentration with in $2 \mathrm{hrs}$ [6]. However, it has a short biological half-life of $2 \mathrm{hrs}$, which means that frequent doses are required to maintain the therapeutic efficacy over extended time periods.

These problems can be solved by the preparation of polymeric prodrug backbones which can contain drugs in a physically bound (dissolved, dispersed, included or adsorbed) state or by true chemical linkages along the polymer backbone or as side groups. These latter systems, in which drugs are delivered by chemically or biologically induced cleavage of the covalent bonds, allow one to achieve a more constant release of the drug for long periods of time. The use of polymers as prodrugs of bioactive agents can thus decrease the required dose, and then the toxicity of the drug, making its solubility and therapeutic efficiency better [7]. In modern era, some NSAIDs such as Ibuprofen, Indomethacin, Ketoprofen and Diclofenac were covalently attached to various polymer backbones and their hydrolysis studied.

The biologically active drug and a polymer conjugation is one of the numerous methods for changing and controlling the pharmacokinetics, biodistribution and often toxicity of these compounds [8-13]. The preparation of a drug-polymer conjugate has been reported widely in many reviews [14-21]. Recently, polymeric prodrugs having Ibuprofen pendent groups were prepared by the free radical polymerization of new polymerizable acrylic monomer with various co monomers. For controlled drug release, this lbuprofen-dextran ester prodrug improved lbuprofen solubility and achieving prolonged release properties [20-22]. a-methyl, ethyl and propyl glucopyranoside esters conjugate of Ibuprofen and glyceride prodrugs was reported to have less ulcerogenicity with better anti-inflammatory/analgesic action than their parent drug when administered orally [24,25]. A conjugate with $\beta$-cyclodextrin was prepared by covalent bonding to one of the primary hydroxyl groups of $\beta$-cyclodextrin for enhanced Solubility and Dissolution [26, 27]. Drugs that contain reactive functional groups such as carboxyl or hydroxyl groups can be converted to a wide variety of polymerizable derivatives.

In this study poly (ethylene glycol) is being used as the carrier polymer, because it is known to be non-toxic, non-antigenic, non-teratogenic, non-immunogenic, biocompatible, available in variety of molecular weights, linear, uncharged, and amphiphilic polymer, soluble in water and in most organic solvents and has solubilizing properties, rapidly eliminated from the body, and has been approved for a wide range of biomedical applications [15-18, 28]. Considering all these general properties and advantages of PEG, in this research work, we selected PEG as a polymer drug carrier and Ibuprofen as a small molecular drug which was covalently linked to PEG for preparing PEG-lbu prodrug. By using PEGs with different molecular weights, two polymer prodrugs were synthesized, and their detailed molecular structures were characterized via ${ }^{1} \mathrm{H}$ NMR and FTIR techniques. This study aimed to suggest that PEG-Ibu prodrug obtained could be a promising NSAID prodrug with improved solubility, Furthermore, study in vitro on drug release from these 
prodrugs in various media demonstrated that extended pharmacological effect owing to delayed-release of parent drug for Ibuprofen has been achieved significantly.

\section{Experimental}

\section{Material}

Ibuprofen was obtained from Unisule, sonipat. 4-Dimethylaminopyridine (DMAP) and N,N'-dicyclohexylcarbodiimide (DCC) were obtained from Spectrochem, Mumbai. Poly(ethylene glycol) with a molecular weight of 600 and 4000 was obtained from E.Merck, Mumbai. All other chemicals were of reagent grade and used without further purification.

\section{Analytical methods}

The infrared absorption spectra of the Ibuprofen, PEG and PEG-Ibu were obtained using a FT-IR spectrophotometer (FT/IR- $8400 \mathrm{~S}$, Shimadzu, Japan). The samples were pressed into a potassium bromide pellet before obtaining their IR absorption spectra. The ${ }^{1} \mathrm{H} N M R$ spectra were obtained on a Bruker 400 Spectrometer (Bruker Avance-II 400 NMR Spectrometer SAIF, Panjab University, Chandigarh). Ultraviolet-visible spectra were recorded on a Thermospectronic UV 1 Double beam spectrophotometer (Merck, Mumbai). DSC (Shimandzu corporation, DSC-TA-GOWS-(U220 230V), Serial no. C-30454700909) was used to determine the thermal behaviors of Ibuprofen and prodrugs.

\section{Methods}

\section{Preparation and characterization of the PEG-Ibuprofen conjugate}

Preparations of the PEG 600 -lbuprofen conjugate (PEG-Ibu)

Poly (ethylene glycol) $6005.38 \mathrm{gm}$. (8mmol) and DCC $6.592 \mathrm{gm}$. (16mmol) were dissolved in methylene chloride followed by the addition of Ibuprofen $3.3 \mathrm{gm}(16 \mathrm{mmol})$ and DMAP $0.293 \mathrm{gm}$. $(2.4 \mathrm{mmol})$. The mixture was stirred, and a white precipitate of dicyclohexylurea (DCU) was formed after 15-30 min. The reaction was monitored by thin layer chromatography (TLC). After approximately 6-8 h, the precipitate was filtered and the filtrate was evaporated to dryness. The resulting residue was dissolved in acetone, filtered to further remove any DCU, and evaporated again. 10\% sodium bicarbonate was used to separate the PEG-Ibu from free Ibuprofen. Column chromatography was used to separate the PEG-Ibu from the reaction mixture. In order to remove the DMAP, a methanol/methylene chloride (9/91): hexane/ethyl acetate (1/2) mixture at a ratio of 20:1 was used as the mobile. The purified products were dried under vacuum. The pure $P E G_{600}-$ lbu conjugate with the yield of $60.49 \%$ was obtained. The fact that there was no free drug of Ibu existing in polymer prodrug was confirmed by thin layer chromatography and DSC measurements.

\section{Preparations of the PEG 4000 -Ibuprofen conjugate (PEG $\left.\mathrm{G}_{4000}-\mathrm{Ibu}\right)$}

The same procedure was used to prepare $P E G_{4000}-1 b u$ as mentioned above. In this case, Poly (ethylene glycol) $40008 \mathrm{gm}$. $(2 \mathrm{mmol})$ and DCC $1.648 \mathrm{gm}$. $(4 \mathrm{mmol})$ were dissolved in dichloromethane followed by the addition of 2-(4-isobutylphenyl) propanoic acid (Ibuprofen) $0.825 \mathrm{gm}$. (4mmol) and DMAP $0.1466 \mathrm{gm}$. (0.6mmol). Yield: $57.57 \%$ 


\section{Determination of Drug Solubility}

To determine the drug solubility, an excess amount of pure Ibuprofen, $P E G_{4000}-I b u$ conjugate and $P E G_{600}-I b u$ conjugate were added to distilled water and Phosphate Buffer ( $\mathrm{pH}$ 7.4). This suspension was stirred at room temperature for 24 hours with a Rota spin test tube Roter. After that the containers (test tubes) were left overnight for saturation. Then these saturated solutions were centrifuged at $10000 \mathrm{rpm}$ the help of macro centrifuge and the supernatant was filtered via Whatman filter paper. The concentration of Ibuprofen was determined spectrophotometrically at $222 \mathrm{~nm}$ [29-31].

\section{Drug release tests via hydrolysis}

The hydrolysis rates of the synthesized conjugates were studied in vitro in artificial gastric juice $\mathrm{pH} 1.2$ and in Phosphate buffer solution $\mathrm{pH}$ 7.4. The reaction was monitored by UVVisible spectrophotometer for the increase in concentration of free drug with time.

\section{(a) Hydrolysis in $0.2 \mathrm{M}$ hydrochloric acid buffer ( $\mathrm{pH}$ 1.2)}

$\mathrm{PEG}_{600}-\mathrm{lbu}$ and $\mathrm{PEG}_{4000}-\mathrm{lbu}$ (wt. equivalent to $10 \mathrm{mg}$ of Ibuprofen) were taken and introduced in $900 \mathrm{ml} \mathrm{HCl}$ buffer $(\mathrm{pH} \mathrm{1.2)}$ taken in the separate baskets in USP dissolution apparatus type-I and were kept in a constant temperature bath at $37 \pm 1{ }^{\circ} \mathrm{C}$. The solutions were occasionally stirred and $5 \mathrm{ml}$ aliquot of both conjugates were withdrawn at various time intervals and were transferred to $10 \mathrm{ml}$ volumetric flasks. The sink conditions were maintained by replacement of equal volume of fresh dissolution medium. Standerd curve were made by pure Ibuprofen in buffer solution using UV spectrophotometer at $222 \mathrm{~nm}$. The concentration of Ibuprofen released was analyzed and calculated by comparing the slope of standard curve at $222 \mathrm{~nm}$. Experiments was repeated three times.

\section{(b) Hydrolysis in $0.2 \mathrm{M}$ phosphate buffer (pH 7.4)}

Same procedure as described in (a) was followed for $P E G_{600}-$ lbu and $P E G_{4000}-l b u$, where instead of $\mathrm{HCl}$ buffer, phosphate buffer $\mathrm{pH} 7.4$ was used. Percentage of drug released was calculated. Studies were carried out in triplicate.

\section{Biological Evaluation}

All the animals were obtained from the animal house of the Department of Pharmacology, B.R. Nahata College of Pharmacy, Mandsaur and its animal facility is approved by CPCSCA (Reg. No. 918/ac/05/CPCSEA). The experimental protocols for the same have been approved by Institutional Animal Ethics Committee. The analgesic activity was carried out on Swiss albino mice by the Siegmund et al. method; anti-inflammatory activity of the compounds was carried out on Wistar rats by the Winter et al. method [25, 32].

\section{Writhing Induced by Acetic Acid}

Analgesic activity was carried out by using acetic acid induced writhing method in Swiss albino mice $(25-30 \mathrm{~g})$ of either sex. A $1 \% \mathrm{v} / \mathrm{v}$ solution of acetic acid was used to induce writhing. Test compounds were administered orally $3 \mathrm{~h}$ prior to acetic acid injection. Number of writhing for $10 \mathrm{~min}$ in control and test compounds were counted and compared. To evaluate the analgesic activity of the conjugates 4 groups of animals $(n=6)$ were examined. A first group of rats was used as a control receiving vehicle $5 \mathrm{ml} \mathrm{kg}{ }^{-1}$, while group II received Ibuprofen (20 $\mathrm{mg} \mathrm{kg}^{-1}$ ), groups III and IV received PEG 600 -lbu conjugate 
and $\mathrm{PEG}_{4000}$-lbu conjugate (52.60 $\mathrm{mg} \mathrm{kg}^{-1}$ and $214 \mathrm{mg} \mathrm{kg}^{-1}$ respectively), where the dose of conjugate was molecularly equivalent to Ibuprofen. A stock solution of $0.2,0.52$ and $2.14 \mathrm{mg} \mathrm{ml}^{-1}$ was prepared as a homogeneous suspension in aqueous solution of sodium CMC $(0.5 \% \mathrm{w} / \mathrm{v})$ and each animal received $2.0-2.2 \mathrm{ml}$ of the respective drugs orally. Acetic acid was administered intraperitoneally $1 \mathrm{ml} / 100 \mathrm{~g}$ body weight of the animal. Analgesic activity was measured as percent decrease in writhing in comparison to control. The percent Inhibition was calculated using the following equation:

$$
\% \text { Inhibition }=100-\frac{\text { number of writhings in test }}{\text { number of writhings in control }} \times 100
$$

\section{Carrageenan-Induced paw edema}

The anti-inflammatory activity was evaluated using carrageenan-induced paw edema on rat method. To evaluate the anti-inflammatory activity of the conjugates 4 groups $(n=6)$ of Wistar rats (150-200 g) were examined. A first group of rats was used as a control without using the drug, group II received Ibuprofen $20 \mathrm{mg} \mathrm{kg}^{-1}$, received $P E G_{600}$-lbu conjugate and $\mathrm{PEG}_{4000}$-lbu conjugate (52.60 $\mathrm{mg} \mathrm{kg}^{-1}$ and $214 \mathrm{mg} \mathrm{kg}^{-1}$ respectively), where the dose was molecularly equivalent to the Ibuprofen. A stock solution of $0.2,0.52$ and $2.14 \mathrm{mg} \mathrm{ml}^{-1}$ was prepared as a homogeneous suspension in aqueous solution of sodium CMC $(0.5 \% \mathrm{w} / \mathrm{v})$ and each animal received $2.0-2.2 \mathrm{ml}$ of the respective drugs orally. Thirty minutes after administration of drugs, each rat received a subplanter injection of $0.1 \mathrm{ml}$ of $1 \%$ carrageenan solution in its left hind paw. The swelling volume of the paw was measured before (time 0 ) and at $0.5,1,2,3,4,24 \mathrm{~h}$ after the carrageenan injection. The measurement of the hind paw volume was carried out using an Ugo Basile Plethysmometer before any treatment (Vo) and in any interval ( $V t$ ) after the administration of the drugs. The percentage increase in the paw volume was calculated from the normal paw volume. The percentage of swelling inhibition was calculated using:

$$
\text { Inhibition }(\%)=\frac{(\mathrm{Vt}-\mathrm{Vo})_{\text {control }}-(\mathrm{Vt}-\mathrm{Vo})_{\text {treated }}}{(\mathrm{Vt}-\mathrm{Vo})_{\text {control }}} \times 100
$$

( $V t$ and Vo relates to the average volume in the hind paw of the rats $(n=6)$ before any treatment and after anti-inflammatory agent treatment, respectively.

\section{Statistical Analysis}

All the results are expressed as mean \pm S.E.M. Statistical evaluation was performed using analysis of variance followed by Dunnet's $t$-test for sub group comparison. A $P$ value $<0.001$ was considered significant.

\section{Results and discussion}

\section{Preparation of PEG-Ibu conjugate}

In this work, PEG-Ibu was synthesized by the esterification of the carboxyl group of Ibuprofen with the hydroxyl group of PEG at room temperature, as shown in Fig. 1. 


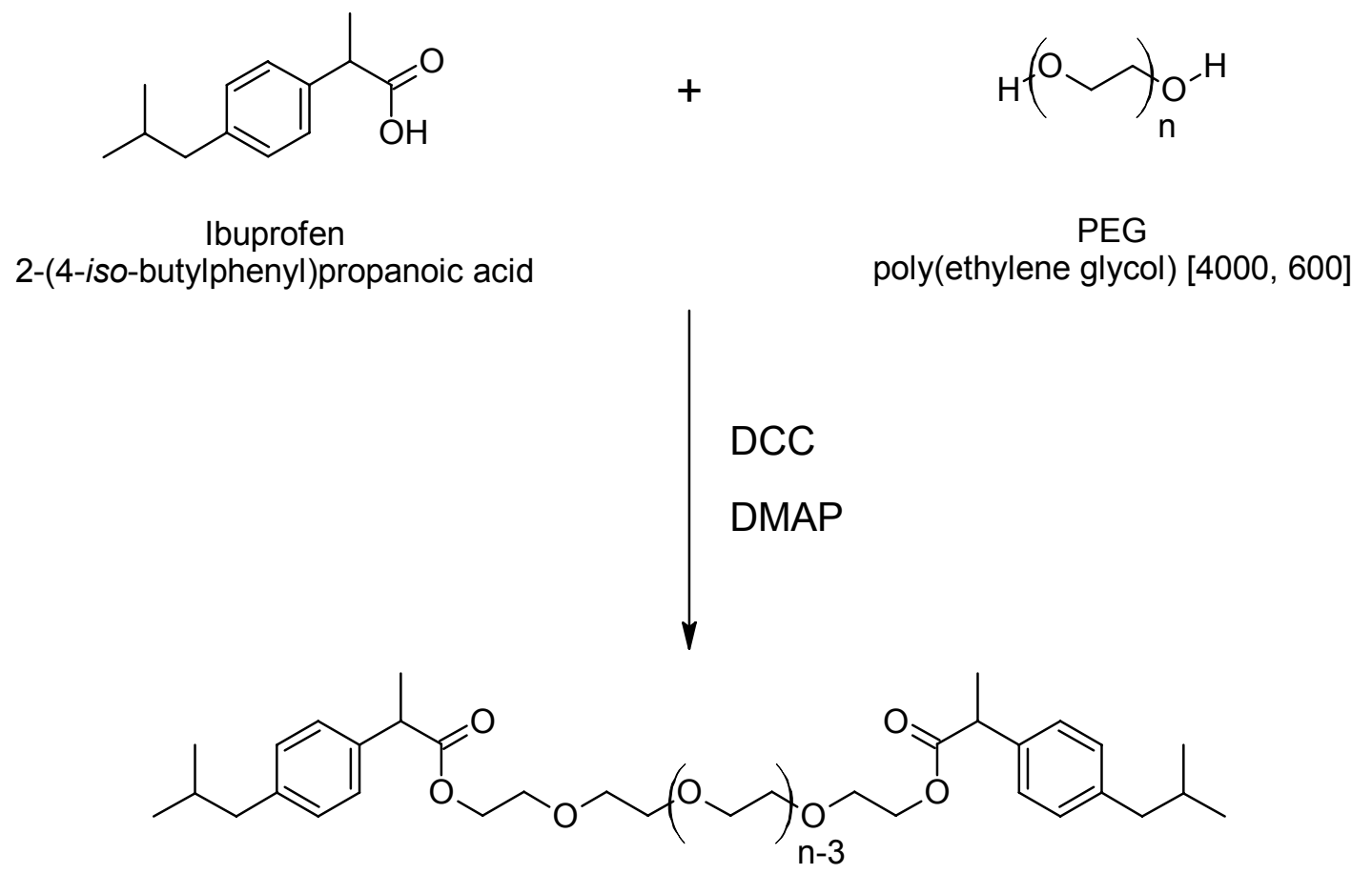

PEG-Ibuprofen conjugate

Fig. 1. Synthesis of the PEG-Ibuprofen conjugate

The esterification was performed using DCC as the coupling agent and DMAP as a catalyst [33]. The conjugation between Ibuprofen and PEG was confirmed by FT-IR and ${ }^{1} \mathrm{H}$ NMR. The position of peak on IR spectrum for $P E G_{4000}-\mathrm{lbu}$ conjugate was assigned as follows; IR (pellet): $2876.8,1731,1512,1113 . \mathrm{cm}^{-1}$. When conjugated, the hydroxyl groups of Ibuprofen and PEG are expected to disappear due to the esterification process. The carbonyl peak of Ibuprofen appearing at $1710 \mathrm{~cm}^{-1}$ due to intermolecular hydrogen bonding will be shifted to a higher frequency after conjugation with PEG. In addition, larger and sharper aliphatic stretching band of $\mathrm{C}-\mathrm{H}$ will appear, due to the increased number of $\mathrm{C}-\mathrm{H}$ bonds by PEG. As shown in Fig. 2, there was no hydroxyl peak in the PEG 4000 spectrum and the carbonyl peak shifted to $1731 \mathrm{~cm}^{-1}$. Also, the larger and sharper $\mathrm{C}-\mathrm{H}$ stretching band appeared at $2876.8 \mathrm{~cm}^{-1}$.

At room temperature, $\mathrm{PEG}_{600}$-lbu was oily, and the $\mathrm{PEG}_{4000}$-lbu was solid. All the conjugates were soluble in water and organic solvents such as ethanol, chloroform and dichloromethane. Fig. 3 shows the chemical shift of the $\mathrm{PEG}_{4000}$-lbu measured by ${ }^{1} \mathrm{H}$ NMR. PEG 4000 -lbu: ${ }^{1} \mathrm{H}$ NMR $\left(400 \mathrm{MHz}, \mathrm{CDCl}_{3}, \mathrm{ppm}\right): \delta 0.90\left[\mathrm{~d}, 12 \mathrm{H},-\mathrm{CH}\left(\mathrm{CH}_{3}\right)_{2}\right], 1.47$ [d, $\left.6 \mathrm{H},-\mathrm{CHCH}_{3}\right], \quad 1.80-1.87\left[\mathrm{~m}, 2 \mathrm{H},-\mathrm{CH}\left(\mathrm{CH}_{3}\right)_{2}\right], 2.42\left[\mathrm{~d}, 2 \mathrm{H},-\mathrm{CH}_{2}\right], 3.38-3.83$ [m, $-\mathrm{O}\left(\mathrm{OCH}_{2} \mathrm{C}_{2}\right) \mathrm{n}$ ], 3.69-3.75 [q, $\left.2 \mathrm{H},-\mathrm{CH}^{\mathrm{HC}} \mathrm{H}_{3}\right], 4.17-4.24\left[\mathrm{~m}, 4 \mathrm{H}, \mathrm{CO}_{2} \mathrm{C}_{2}\right], 7.07-7.29[\mathrm{~m}$, $8 \mathrm{H}, \mathrm{Ar} \mathrm{H}]$. The pegylation was confirmed by disappearance of the signal of the carboxylic acid at $11.23 \mathrm{ppm}$ and appearance of $-\mathrm{CO}_{2} \mathrm{C}_{2}$-protons at $4.2 \mathrm{ppm}$. 


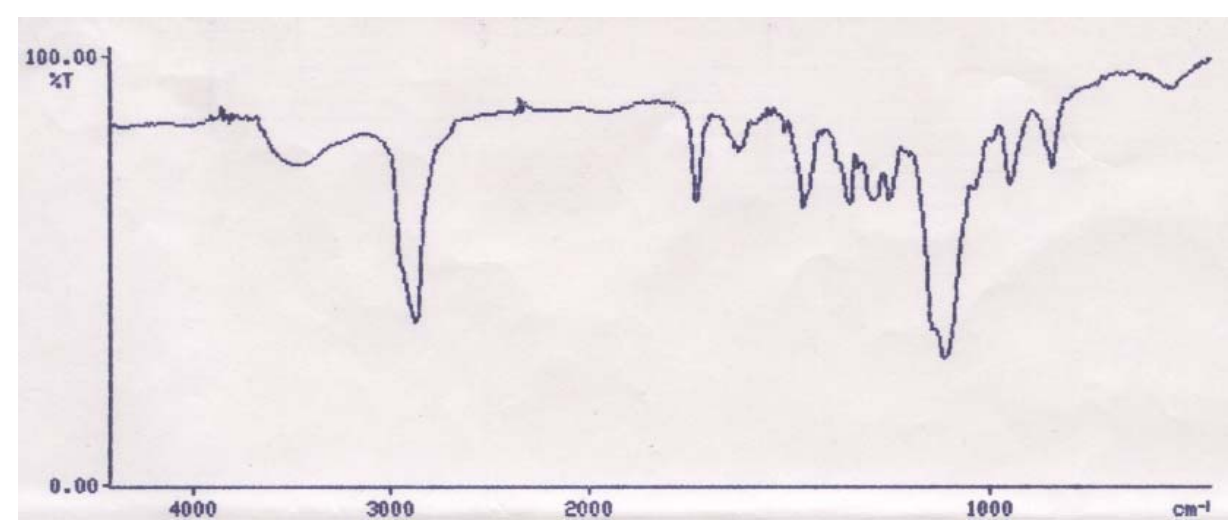

Fig. 2. FTIR OF PEG ${ }_{4000}$-lbu conjugate

The position of each peak in IR and NMR spectrum for $\mathrm{PEG}_{600}$-lbu: IR (KBr pellet): 2885.8 , 1734.2, 1467.2, $1114.1 \mathrm{~cm}^{-1} .{ }^{1} \mathrm{H}$ NMR $\left(400 \mathrm{MHz}, \mathrm{CDCl}_{3}, \mathrm{ppm}\right): \delta 0.89[\mathrm{~d}, 12 \mathrm{H}$, $\left.-\mathrm{CH}\left(\mathrm{CH}_{3}\right)_{2}\right], 1.46\left[\mathrm{~d}, 6 \mathrm{H},-\mathrm{CHCH}_{3}\right], 1.53-1.58\left[\mathrm{~m}, 2 \mathrm{H},-\mathrm{C} \underline{\mathrm{H}}\left(\mathrm{CH}_{3}\right)_{2}\right], 2.44$ [d, $\left.2 \mathrm{H},-\mathrm{CH}_{2}\right], 3.54-$ $3.72\left[\mathrm{~m},-\mathrm{O}\left(\mathrm{OCH}_{2} \mathrm{C}_{2}\right) \mathrm{n}\right], 3.65-3.72$ [q, 2H, $-\mathrm{CHCH}_{3}$ ], 4.10-4.19 [m, 4H, $\mathrm{CO}_{2} \underline{\mathrm{C}}_{2}$ ], $7.06-$ $7.21[\mathrm{~m}, 8 \mathrm{H}, \mathrm{Ar} \underline{\mathrm{H}}]$.

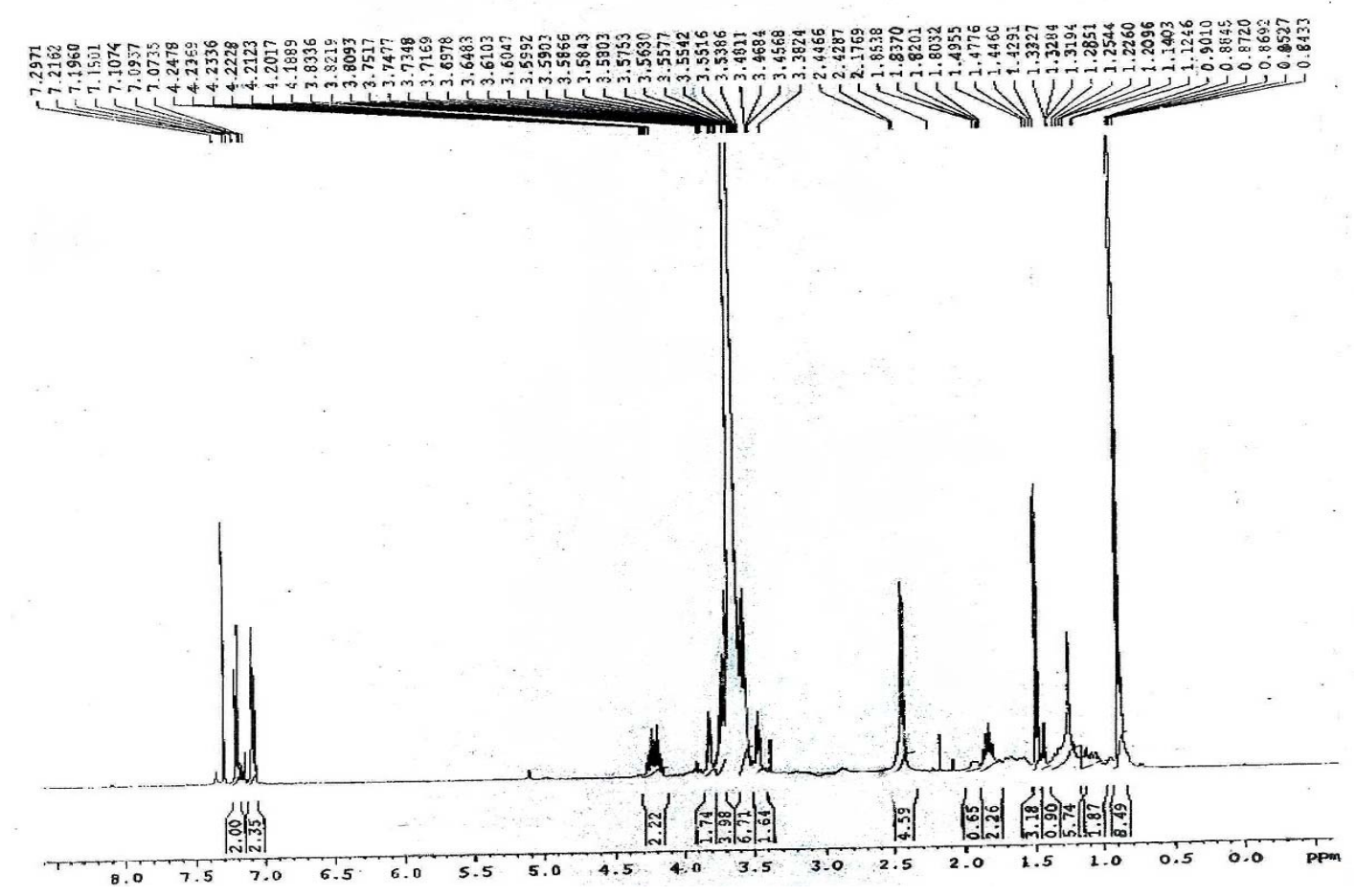

Fig. 3. $\quad{ }^{1} \mathrm{HNMR}$ spectra of PEG 4000-lbuprofen Conjugate

Additionally, thin layer chromatography, DSC was used for determining free lbuprofen in polymer prodrug, and the results as shown in Fig. 4. Pure Ibuprofen melting point was at $79.69^{\circ} \mathrm{C}$ on its DSC thermogram, and $P E G_{4000}-l b u$ was at $58.73^{\circ} \mathrm{C}$. However no peak was visible near the lbuprofen's melting point for the polymeric conjugate thermogram. 


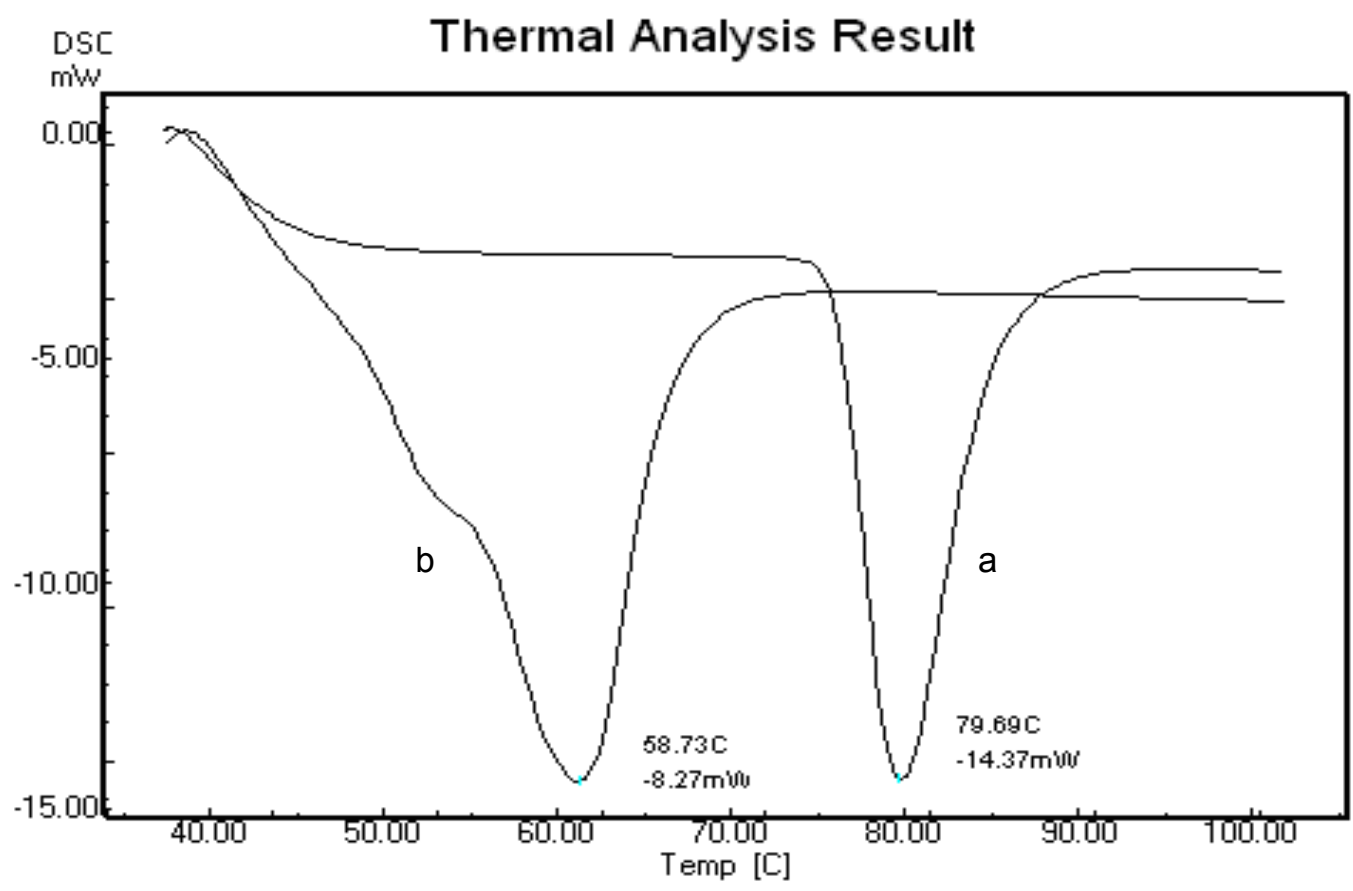

Fig. 4. DSC-thermogram of pure Ibuprofen (a), $P E G_{4000}-I b u$ conjugate (b)

\section{Aqueous Solubility}

Physicochemical parameter such as aqueous solubility has been shown to influence membrane flux, therapeutic activity, and pharmacokinetic profiles of medicines. The solubility of Ibuprofen in distilled water has been previously found to be $10.57 \mathrm{mcg} / \mathrm{mL}$. In this study, the solubility of $P E G_{600}$-lbuprofen and $P E G_{4000}$-lbuprofen conjugates in distilled water were $24.48 \mathrm{mcg} / \mathrm{mL}$ and $50.57 \mathrm{mcg} / \mathrm{mL}$ respectively. The solubility of Ibuprofen in phosphate buffer $(\mathrm{pH} 7.4)$ has been previously found to be $25.16 \mathrm{mcg} / \mathrm{mL}$ and solubility of $P E G_{600}$-lbuprofen and $\mathrm{PEG}_{4000}$-lbuprofen conjugates in phosphate buffer $(\mathrm{pH} 7.4)$ were $41.97 \mathrm{mcg} / \mathrm{mL}$ and $57.21 \mathrm{mcg} / \mathrm{mL}$ respectively. As may be noted in Fig. 5 and 6, Ibuprofen water solubility was less while for $\mathrm{PEG}_{600}$-lbuprofen and $\mathrm{PEG}_{4000}$-lbuprofen conjugates an increase of this parameter was observed. From the solubility data we can conclude that $\mathrm{PEG}_{4000}$-lbu conjugate is more hydrophilic in nature.

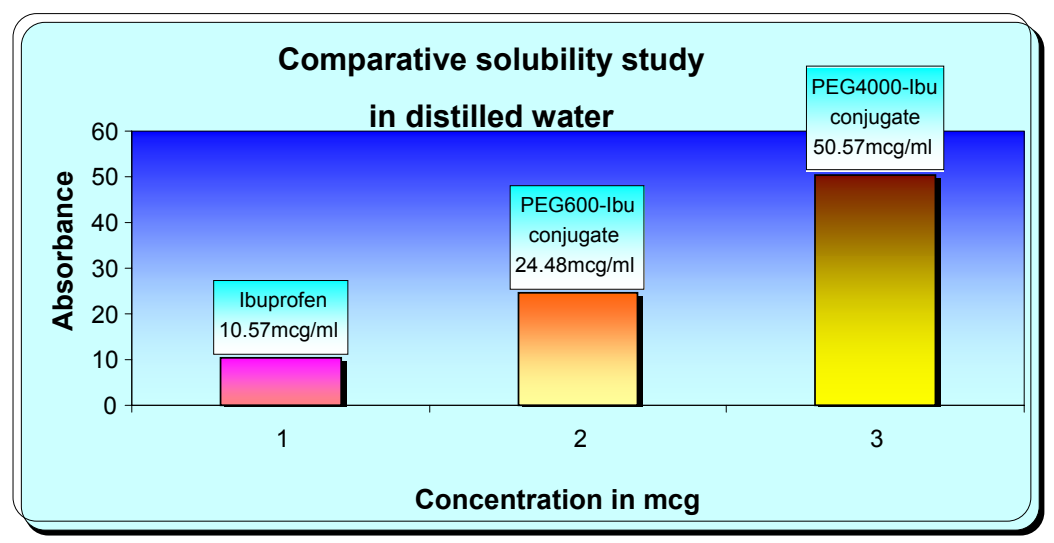


Fig. 5. Comparative Solubility Study in Distilled Water

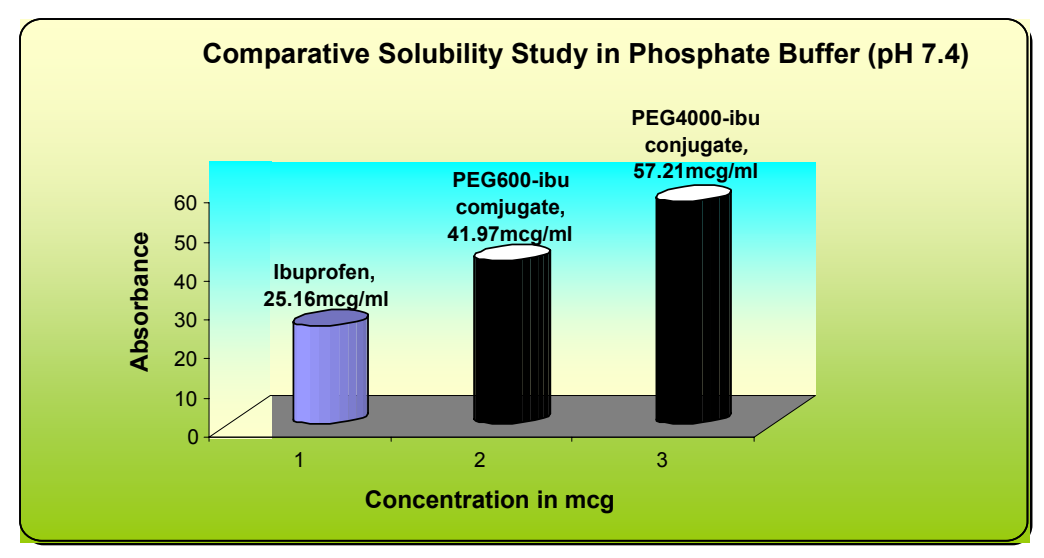

Fig. 6. Comparative Solubility in Phosphate Buffer $(\mathrm{pH} 7.4)$

\section{In vitro Hydrolysis Studies}

In order to obtain some preliminary information about the potential use of the PEG-Ibu as a drug delivery system for a prolonged release, hydrolysis process for two prodrugs is studied in buffer solutions at $\mathrm{pH} 1.2$ and 7.4. This study shows whether the prodrugs hydrolyze in these buffer solutions and to what extent, providing an idea of the fate of the prodrug in-vivo.

On the one hand comparison of the release profile of Ibuprofen conjugates (PEG ${ }_{600}-\mathrm{lbu}$ and $\mathrm{PEG}_{4000}$-lbu conjugates) in $0.2 \mathrm{M} \mathrm{HCl}$ buffer $(\mathrm{pH} 1.2)$ revealed that $\mathrm{PEG}_{600}-\mathrm{Ibu}$ and $\mathrm{PEG}_{4000}$-lbu conjugates were hydrolysed to an extent of $64.35 \%$ and $43.9 \%$ at pH 1.2 after $8 \mathrm{hrs}$ and this percentage still increases by time reaching $87.26 \%$ and $71.2 \%$ after $24 \mathrm{hrs}$ for $\mathrm{PEG}_{600}$-lbu and $\mathrm{PEG}_{4000}$-lbu conjugate respectively (Fig. 7).

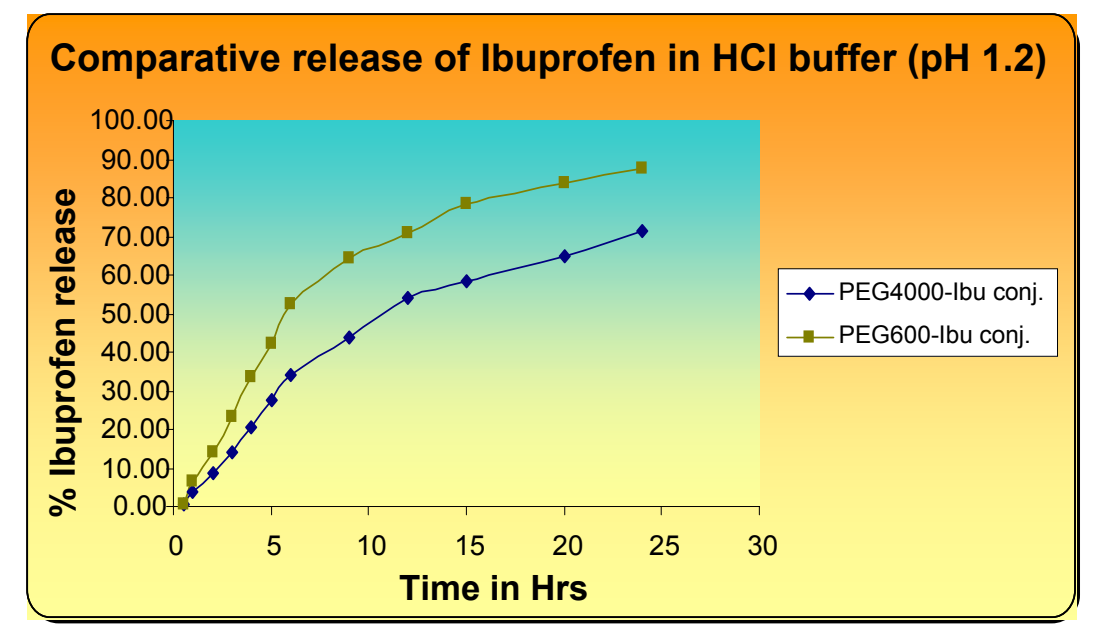

Fig. 7. Comparative release of Ibuprofen in $\mathrm{HCl}$ buffer $(\mathrm{pH} 1.2)$ 
On the other hand, Ibu-release from the conjugates in $0.2 \mathrm{M}$ phosphate buffer $(\mathrm{pH} 7.4)$ amounted to $83.1 \%\left(\mathrm{PEG}_{600}-\mathrm{lbu}\right)$ and $71.2 \%\left(\mathrm{PEG}_{4000}-\mathrm{lbu}\right)$ after $8 \mathrm{hrs}$ and further increased 98.3 and $89.0 \%$ in 24 hrs for $P E G_{600}-$ Ibu and $P E G_{4000}$-lbu conjugate respectively (Fig. 8). The hydrolysis rate of Ibuprofen from $\mathrm{PEG}_{600}-\mathrm{lbu}$ and $\mathrm{PEG}_{4000}-\mathrm{lbu}$ conjugates was calculated to be $8 \%$ and $5 \%$ per hour at $\mathrm{pH} 1.2$ and $16 \%$ and $9 \%$ at $\mathrm{pH} 7.4$, respectively. This study shows that hydrolysis rate of Ibuprofen from $\mathrm{PEG}_{4000}$-lbu is slower than other.

The dissolution / hydrolysis studies of ester prodrugs indicated a better chemical stability in aqueous buffer solution of acidic $\mathrm{pH} 1.2$ than at nearly neutral $\mathrm{pH} 7.4$. In case of oral administration, this study implies that about 88-90\% intact conjugate reach the intestine provided a mean gastric residence time of the conjugates for two hours.

Another aspect was also cleared that hydrolysis of conjugates decreased with increase in length of PEG and the extended release behavior was found in both conjugates in both $\mathrm{pH}$ 1.2 and 7.4 buffer solutions after 8 hrs. to 24 hrs. (Figs. 7 and 8 ).

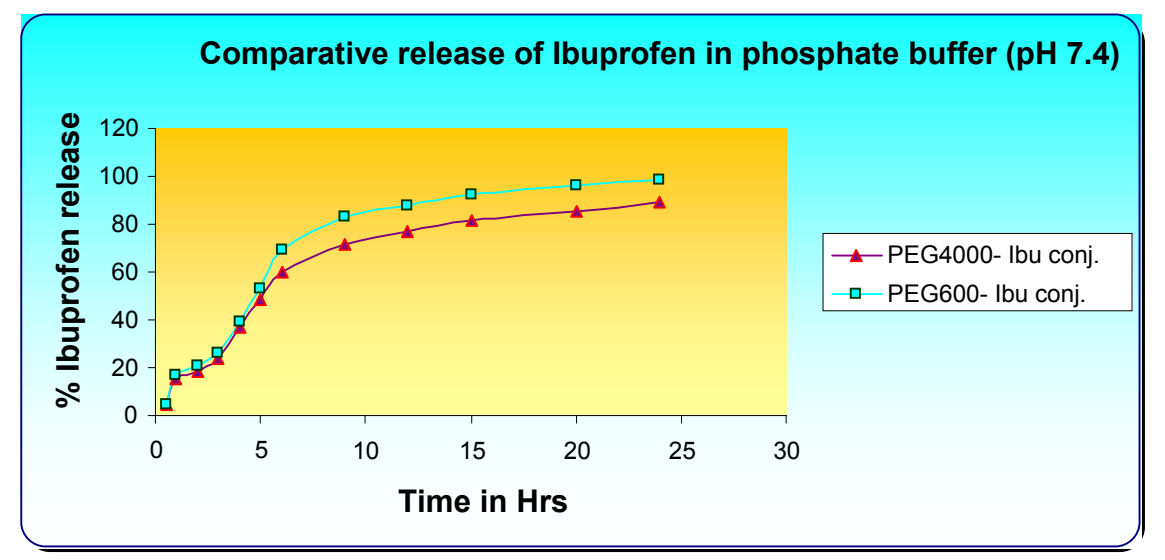

Fig. 8. Comparative Release of Ibuprofen in Phosphate Buffer (pH 7.4)

\section{Analgesic Activity}

Analgesic activity was carried out by using acetic acid induced writhing method in Swiss albino mice $(25-30 \mathrm{~g})$ of either sex. A $1 \% \mathrm{v} / \mathrm{v}$ solution of acetic acid was used to induce writhing. Test compounds were administered orally $3 \mathrm{~h}$ prior to acetic acid injection. The $P E G_{600}-$ lbu conjugate and $P E G_{4000}$-lbu conjugate showed analgesic activity comparable to the parent drug. The percent protection in mice brought about by administration of the drugs. In writhing model, Ibuprofen and all its prodrugs ( $P E G_{600}-\mathrm{lbu}$ conjugate and $\mathrm{PEG}_{4000}$-lbu conjugate) presented remarkable reduction of writhing number if compared to control group (Fig. 9).

Ibuprofen administrated $3 \mathrm{hr}$. prior to testing produced a significant decrease $(59.61 \%)$ in writhing number versus control values Moreover, both conjugate $P E G_{600}$-lbu conjugate and $P E G_{4000}-\mathrm{lbu}$ conjugate were equally effective in reducing the writhing response $(57.10 \%$ and $59.02 \%$ respectively) at molecular equivalent quantity. however, no appreciable difference could be observed among all prodrugs with respect to their analgesic activity. 
Effect of Ibuprofen and its Conjugates

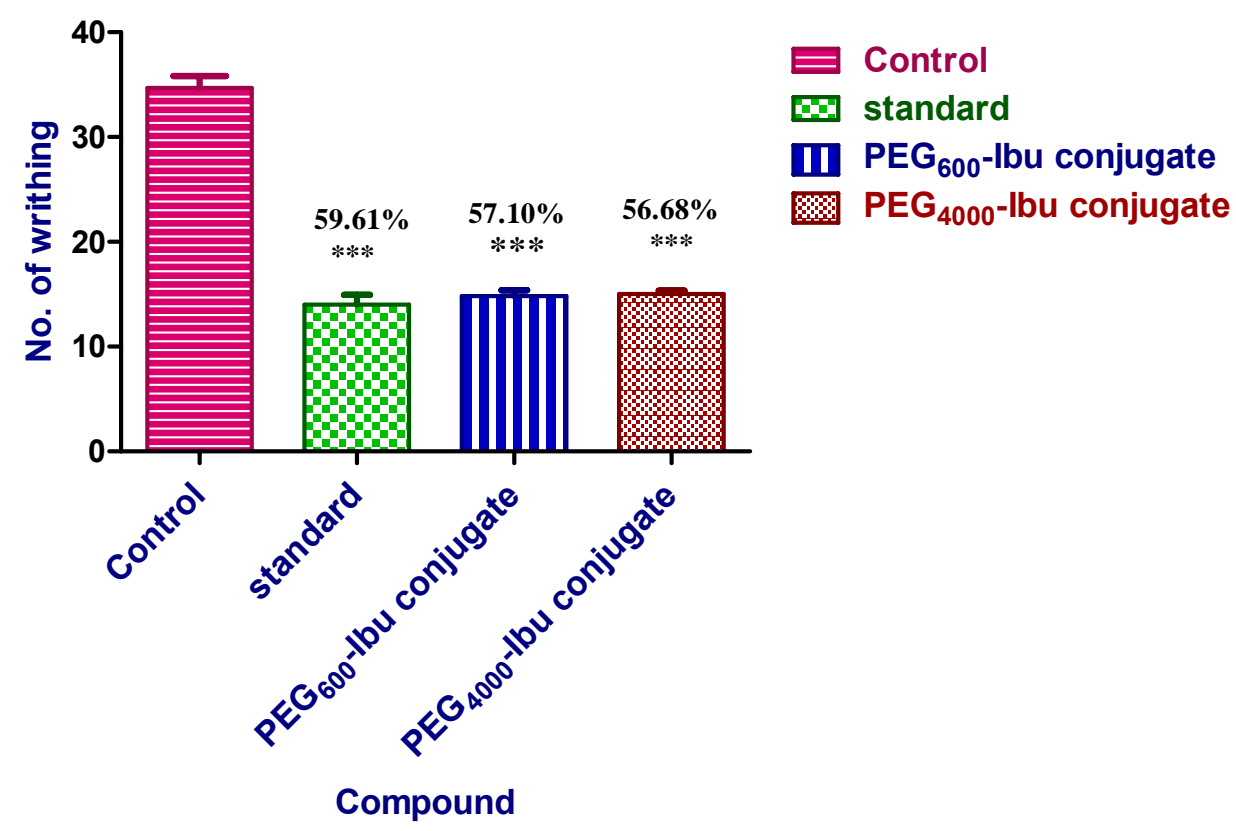

Fig. 9. Effect of ibuprofen and its conjugates (PEG $\mathrm{PG}_{60}-\mathrm{lbu}$ and $\left.P E \mathrm{G}_{4000}-\mathrm{lbu}\right)$ on acetic acid induced writhing in mice. Data represent mean values ( \pm S.D.) and percent inhibition (\%) compared to the control animals. Statistical differences versus control group are indicated by asterisks $\left\{N=6\right.$, one-way ANOVA, $\left(p<0.05\left(^{*}\right)\right.$, $\left.p<0.01{ }^{* *}\right)$ and $\left.p<0.001\left(^{* * *}\right)\right\}$.

\section{Anti-inflammatory Activity}

Table 2 shows the effect of Ibuprofen, $P E G_{600}$-lbu and $P E G_{4000}$-lbu conjugates on the volume of acute inflammatory paw edema in rats caused by carrageenan after oral administration. Although the peak anti-inflammatory effects of $P E G_{600}$-lbu conjugate and $\mathrm{PEG}_{4000}-\mathrm{Ibu}$ conjugate occurred later than lbuprofen, but it exhibited a significantly extended anti-inflammatory activity compared with Ibuprofen. The maximum antiinflammatory activity of prodrugs ( $P E G_{600}$-lbu conjugate and $P E G_{4000}$-lbu conjugate) was observed at 3-4 $\mathrm{h}$ and remained practically constant up to $8 \mathrm{~h}$. The anti-inflammatory activity of free lbuprofen however decreased with time.

Statistical significance testing using one way analysis of variance showed that the antiinflammatory activity of ibuprofen and prodrugs were effective in comparison with the control group. However, differences in the potency of anti-inflammatory activity of the prodrugs compared to the free ibuprofen were observed over a long period $(8 \mathrm{~h})$. Thus $\mathrm{PEG}_{600}$-lbu conjugate and $\mathrm{PEG}_{4000}$-lbu conjugate were investigated to be a suitable promoiety for Ibuprofen. 
Tab. 2. Percentage of Inhibition Caused by Ibuprofen and Its Conjugates in Carrageenan-Induced edema in Wistar rats (150-200 g)

\begin{tabular}{|c|c|c|c|c|c|c|c|}
\hline Treatment & $\begin{array}{c}\text { Dose } \\
(\mathrm{mg} / \mathrm{kg})\end{array}$ & $1 \mathrm{hr}$. & $2 \mathrm{hr}$ & $3 \mathrm{hr}$ & $4 \mathrm{hr}$ & $8 \mathrm{hr}$ & $24 \mathrm{hr}$ \\
\hline Control & - & $\begin{array}{l}0.59 \pm \\
0.005\end{array}$ & $\begin{array}{l}0.68 \pm \\
0.007\end{array}$ & $\begin{array}{l}0.48 \pm \\
0.009\end{array}$ & $\begin{array}{c}0.43 \pm \\
0.011\end{array}$ & $\begin{array}{l}0.32 \pm \\
0.005\end{array}$ & $\begin{array}{l}0.27 \pm \\
0.006\end{array}$ \\
\hline Standard & 20 & $\begin{array}{c}0.33 \pm \\
0.013^{* *}\end{array}$ & $\begin{array}{c}0.48 \pm \\
0.017^{* *}\end{array}$ & $\begin{array}{c}0.38 \pm \\
0.013^{* *}\end{array}$ & $\begin{array}{c}0.24 \pm \\
0.009^{* *}\end{array}$ & $\begin{array}{c}0.15 \pm \\
0.010^{\text {ns }}\end{array}$ & $\begin{array}{c}0.03 \pm \\
0.013^{\text {ns }}\end{array}$ \\
\hline $\mathrm{PEG}_{600}$-lbu Conjugate & 52.60 & $\begin{array}{c}0.22 \pm \\
0.008^{* * *}\end{array}$ & $\begin{array}{c}0.33 \pm \\
0.007^{\star * *}\end{array}$ & $\begin{array}{c}0.43 \pm \\
0.012^{* *}\end{array}$ & $\begin{array}{c}0.37 \pm \\
0.014^{* *}\end{array}$ & $\begin{array}{c}0.30 \pm \\
0.009^{* *}\end{array}$ & $\begin{array}{c}0.17 \pm \\
0.010^{* *}\end{array}$ \\
\hline $\mathrm{PEG}_{4000}$-Ibu Conjugate & 214 & $\begin{array}{c}0.25 \pm \\
0.011^{* *}\end{array}$ & $\begin{array}{l}0.36 \pm \\
0.010^{* *}\end{array}$ & $\begin{array}{c}0.45 \pm \\
0.018^{\star *}\end{array}$ & $\begin{array}{c}0.40 \pm \\
0.014^{\star *}\end{array}$ & $\begin{array}{c}0.34 \pm \\
0.007^{* *}\end{array}$ & $\begin{array}{c}0.20 \pm \\
0.011^{* *}\end{array}$ \\
\hline
\end{tabular}

\section{Acknowledgements}

The authors thank the B. R. Nahata College of pharmacy for financial support.

\section{Authors' Statements}

\section{Competing Interests}

The authors declare no conflict of interest.

\section{Animal Rights}

The institutional and international guide for the care and use of laboratory animals was followed. See the methods part for details.

\section{References}

[1] Zhao X, Tao X, Wei D, Song Q.

Synthesis and Study of Controlled Release of Ibuprofen from the New Acrylic Type Polymers. Eur J Med Chem. 2006; 41: 1352-1358. doi:10.1016/j.ejmech.2006.05.014

[2] Guyton CA, Hall JE. In: Textbook of Medical Physiology. Harcourt Asia Pte. Ltd. 1998: 846.

[3] Khan MSY, Akhter M. Synthesis, pharmacological activity and hydrolytic behavior of glyceride prodrugs of ibuprofen. Eur J Med Chem. 2005; 40: 371-376. doi:10.1016/j.ejmech.2004.11.009

[4] Babazadeh M. Synthesis and study of controlled release of Ibuprofen from the new acrylic type polymers. Int J Pharm. 2006; 316: 68-73. doi:10.1016/j.ijpharm.2006.02.032 
[5] Giammona G, Puglisi G, Carlisi B, Pignatello R, Spadaro A, Caruso A.

Polymeric prodrugs: poly ( $N$-hydroxyethyl)-dl-aspartamide as a macromolecular carrier for some nonsteroidal anti-inflammatory agents.

Int J Pharm. 1989; 57: 55-62.

doi:10.1016/0378-5173(89)90263-9

[6] Borne RF.

Nonsteroidal Anti-inflammatory Agents.

In: Foye's Principles of Medicinal Chemistry.

Philadelphia: Lippincott Williams and Wilkins, 2005: 771.

[7] Zacchigna M, Luca GD, Boccu E.

Synthesis, Chemical and Enzymatic Stability of New Poly (ethylene glycol)-Acyclovir Prodrugs.

Farmaco. 2002; 57: 207-214.

doi:10.1016/S0014-827X(01)01193-4

[8] Duncan R, Kopecek J.

Soluble synthetic polymers as potential drug carriers.

Adv Polym Sci. 1984; 57: 53-10.

doi:10.1007/3-540-12796-8_10

[9] Cavallaro G, Licciardi M, Caliceti P, Salmaso S, Giammona G.

Synthesis, physico-chemical and biological characterization of a paclitaxel macromolecular prodrug.

Eur J Pharm Biopharm. 2004; 58: 151-159.

doi:10.1016/j.ejpb.2004.02.012

[10] Cavallaro G, Maniscalco L, Caliceti P, Salmaso S, Semenzato A, Giammona G.

Glycosilated macromolecular conjugates of antiviral drugs with a polyaspartamide.

J Drug Target. 2004; 12: 593-605.

doi:10.1080/10611860400013477

[11] Fuertges F, Abuchowski A.

The clinical efficacy of poly (ethylene glycol)-modified proteins.

J Control Release. 1990; 11: 139-148.

doi:10.1016/0168-3659(90)90127-F

[12] Nichifor M, Schacht EH, Seymour LW.

Macromolecular prodrugs of 5-fluorouracil. 2. Enzymatic degradation.

J Control Release. 1996; 39: 79-92.

doi:10.1016/0168-3659(95)00141-7

[13] Duncan R, Seymour LW, O'Hare KB, Flanagan PA, Wedge S, Wedge IC, Ulbrich K, Strohalm J,

Spreafico F, Grandi M, Ripamonti M, Farao M, Suarato A.

Preclinical evaluation of polymer-bound doxorubicin.

J Control Release. 1992; 19: 331-346.

doi:10.1016/0168-3659(92)90088-9

[14] Hoste K, De Winne K, Schacht E.

Polymeric prodrugs.

Int J Pharm. 2004; 277: 119-131.

doi:10.1016/j.ijpharm.2003.07.016

[15] Choi HK, Chun MK, Lee SH, Jang MH, Kim HD, Jung CS.

In Vitro and In Vivo Study of Poly (ethylene glycol) Conjugated Ketoprofen to Extend the Duration of Action.

Int J Pharm. 2007; 341: 50-57.

doi:10.1016/j.ijpharm.2007.03.045

[16] Zhang J, Fan XD, Liu Y, Bo L, Liu X.

Synthesis of poly (ethylene glycol) - metaxalone conjugates and study of its controlled release in vitro.

Int J Pharm. 2007; 197: 125-131.

doi:10.1016/j.jpharm.2006.09.039 
[17] Bersani C, Berna M, Pasut G, Francesco VM.

PEG-Metronidazole Conjugates: Synthesis, In vitro and In vivo Properties.

Farmaco. 2005; 60: 783-788.

doi:10.1016/j.farmac.2005.04.015

[18] Namazi H, Bahrami S, Entezami AA.

Synthesis and Controlled Release of Biocompatible Prodrugs of $\beta$-Cyclodextrin Linked with PEG

Containing Ibuprofen or Indomethacin.

Iran Polym J. 2005; 14: 921-927.

[19] Khandare J, Minko T.

Polymer-Drug Conjugates: Progress in Polymeric Prodrugs.

Prog Polym Sci. 2006; 31: 359-397.

doi:10.1016/j.progpolymsci.2005.09.004

[20] Dhaneshwar SS, Kandpal M, Gairola N, Kadam SS.

Dextran: A promising macromolecular drug carrier.

Indian J Pharm Sci. 2006; 68: 705-714.

doi:10.4103/0250-474X.31000

[21] Vyas S, Trivedi P, Chaturvedi SC.

Ketorolac-dextran conjugates: Synthesis, in vitro and in vivo evaluation.

Acta Pharm. 2007; 57: 441-450.

doi:10.2478/v10007-007-0035-3

[22] Larsen C, Johansen M.

Macromolecular prodrugs XI: Regeneration rates of various NSAID compounds from their corresponding dextran ester prodrugs in aqueous buffer and in different biological media.

Acta Pharm. 1989; 2: 57-65.

[23] Larsen C, Johansen M.

Macromolecular prodrugs I. Kinetics and mechanism of hydrolysis of O-benzoyl dextran conjugate in aqueous buffer and human plasma.

Int J Pharm. 1985; 27: 205-218.

doi:10.1016/0378-5173(85)90070-5

[24] Zhao X, Tao X, Wei D, Song Q.

Pharmacological activity and hydrolysis behavior of novel ibuprofen glucopyranoside conjugates.

Eur J Med Chem. 2006, 41: 1352-1358.

doi:10.1016/j.ejmech.2006.05.014

[25] Khan MSY, Akhter M.

Synthesis, pharmacological activity and hydrolytic behavior of glyceride prodrugs of Ibuprofen.

Eur J Med Chem. 2005; 40: 371-376.

doi:10.1016/j.ejmech.2004.11.009

[26] Ghorab MK, Adeyeye MC.

Enhancement of ibuprofen dissolution via wet granulation with beta cyclodextrin.

Pharm Dev Technol. 2001; 6: 305-314.

doi:10.1081/PDT-100002611

[27] Challa R, Ahuja A, Ali J, Khar RK.

Cyclodextrins in Drug Delivery: An Updated Review.

AAPS PharmSciTech. 2005; 6: E329-E357.

doi:10.1208/pt060243

[28] Nichifor M, Schacht EH, Seymour LW.

Polymeric prodrugs of 5- fluorouracil.

J Control Release. 1997; 48: 165-178.

doi:10.1016/S0168-3659(97)00048-5 
[29] Ozguney IS, Karasulu HY, Kantarci G, Sozer S, Guneri T, Ertan G.

Transdermal Delivery of Diclofenac Sodium Through Rat Skin From Various Formulations.

AAPS PharmSciTech. 2006; 7: E39-E45.

doi:10.1208/pt070488

[30] Obat Y, Takayama K, Maitani Y, Machida Y, Nagai T.

Effect of ethanol on skin permeation of nonionized and ionized diclofenac.

Int J Pharm. 1993; 89: 191-198.

doi:10.1016/0378-5173(93)90243-9

[31] Kantari G, Ozguney I, Karasulu HY, Güneri T, Başdemir G.

In vitro permeation of diclofenac sodium from novel microemulsion formulations through rabbit skin.

Drug Dev Res. 2005; 65: 17-25.

doi:10.1002/ddr.20003

[32] Vogel GH, Vogel WH.

In: Drug Discovery and Evaluation of Pharmacological Assays.

Springer-Verlag: Berlin, 1997: 669-759.

[33] Zacchigna M, Luca GD, Cateni F, Maurich V.

Improvement of warfarin biopharmaceutics by conjugation with poly (ethylene glycol).

Eur J Pharm Sci. 2004; 23: 379-384.

doi:10.1016/j.ejps.2004.09.001 